\title{
Expression profile of protein kinase $C$ isozymes in preimplantation mouse development
}

\author{
Hesam Dehghani and Ann C Hahnel \\ Department of Biomedical Sciences, University of Guelph, Guelph, Ontario, N1G 2W1 Canada \\ Correspondence should be addressed to A C Hahnel; Email: ahahnel@ovc.uoguelph.ca
}

(H Dehghani is now at Programme in Cell Biology, The Research Institute, The Hospital for Sick Children, Toronto, Ontario, M5G 1 X8 Canada)

\begin{abstract}
In the preimplantation mouse embryo, the protein kinase C (PKC) family has been implicated in regulation of egg activation, progression of meiotic and mitotic cell cycles, embryo compaction, and blastulation, but the involvement of the individual isozymes is largely unknown. Here, using semiquantitative immunocytochemistry and confocal microscopy we analyze the relative amount and subcellular distribution of ten isozymes of PKC $(\alpha, \beta I, \beta I I, \gamma, \delta, \varepsilon, \eta, \theta, \zeta, \mathrm{t} / \lambda)$ and a PKC-anchoring protein, receptor for activated C-kinase 1 (RACK1). Our results show that all of these isoforms of PKC are present between the twocell and blastocyst stages of mouse preimplantation development, and that each has a distinct, dynamic pattern and level of expression. The data suggest that different complements of the isozymes are involved in various steps of preimplantation development, and will serve as a framework for further functional studies of the individual isozymes. In particular, there was a transient increase in the nuclear concentration of several isozymes at the early four-cell stage, suggesting that some of the PKC isozymes might be involved in regulation of nuclear organization and function in the early mouse embryo.

Reproduction (2005) $130441-451$
\end{abstract}

\section{Introduction}

The protein kinase C (PKC) family is a family of serine/threonine protein kinases that plays an important role in cell signal transduction. Based on structural differences that produce differential sensitivity to activators and co-factors, the isozymes have been categorized into three subfamilies. The conventional PKCs (cPKCs) are $\alpha, \beta \mathrm{I}, \beta \mathrm{II}$, and $\gamma$ and are activated by phosphatidylserine, diacylglycerol, $\mathrm{Ca}^{2+}$, and 4 $\beta$-phorbol 12-myristate 13-acetate (4 $\beta$-PMA). The novel PKCs (nPKCs) are $\delta, \varepsilon, \eta$, and $\theta$, and are not $\mathrm{Ca}^{2+}$-dependent, but otherwise activated as the CPKCs. PKC $\mu$ is sometimes included in the nPKCs (Geiges et al. 1997), but it has homologies to both the PKC and calmodulin kinases, and is often placed into a PKC-like family (Hausser et al. 2002). The atypical PKCs (aPKCs) are $\zeta$ and $\iota / \lambda$ and are lipid-dependent, but cannot be activated by either $\mathrm{Ca}^{2+}$ or 4 $\beta$-PMA (Newton 2001). Production of monoclonal antibodies and polyclonal antisera against peptides that distinguish the various isozymes has led to a number of experiments that indicate that individual PKC isozymes are localized differentially within cells before and after stimulation. Their restricted localization exposes them to different substrates and is believed to largely specify function (Schechtman \& Mochly-Rosen
2001). It has been shown that phosphorylation of a group of conserved amino acids determines the activation state of PKC and affects the subcellular localization of each isozyme (Keranen et al. 1995). Also, binding of substrate and non-substrate proteins affects the ability of PKC isozymes to relocate and hence associate with particular substrates (Jaken \& Parker 2000, Mochly-Rosen \& Kauvar 2000, Schechtman \& Mochly-Rosen 2001).

Several studies have established involvement of PKC in egg activation, fertilization, and progression through the meiotic cycles in mice and rats (Gallicano et al. 1995, 1997, Raz et al. 1998, Downs et al. 2001, Viveiros et al. 2001, 2003, Eliyahu \& Shalgi 2002, Quan et al. 2003). However, there is less known of the role of the PKC during early cleavage. Activation with phorbol ester of the CPKC and nPKC blocks progression through the mitotic cycles (Quan et al. 2003). The synthesis of proteins that are required for embryonic gene activation is inhibited by $\mathrm{H} 8$ and $\mathrm{H} 7$, non-specific inhibitors of protein kinases $\mathrm{A}$ and $\mathrm{C}$ that act by competitive inhibition of their ATP-binding sites (Schultz 1993). During mouse preimplantation development, phorbol ester causes premature compaction of two-, four-, and early eight-cell-stage embryos (Ohsugi et al. 1993a, 1993b, 
Ohsugi \& Yamamura 1993), and the non-specific PKC inhibitor D-sphingosine blocks induced and natural compaction (Winkel et al. 1990). PKC $\alpha$ may be involved in compaction, since it redistributes to contact sites as compaction initiates and can phosphorylate $\beta$-catenin (Pauken \& Capco 1999). It has also been demonstrated that blastocoele formation is regulated through phospholipase C (an enzyme that is known to activate PKCdependent pathways; Stachecki \& Armant 1996), and that targeted disruption of mouse phospholipase $C \beta 3$ (the most widely expressed member of the phospholipase $\mathrm{C} \beta$ family) results in early preimplantation death (Wang et al. 1998). Although all of these studies suggest a role for the PKC family in preimplantation development, the relative importance of each isozyme is unknown.

In rat oocytes, Raz et al. (1998) detected PKCs $\alpha, \beta I$, $\beta I I, \gamma, \delta, \varepsilon, \lambda$, and $\zeta$ by Western blot and immunocytochemistry with isozyme-specific antibodies, but not PKCs $\theta$ or $\mathbf{\iota}$, and Eliyahu \& Shalgi (2002) detected PKCs $\alpha, \beta \mathrm{I}$, and $\beta \mathrm{II}$ by immunocytochemistry. PKCs $\alpha, \beta \mathrm{I}$, and $\gamma$ have been detected in pig oocytes (Fan et al. 2002). The studies of mouse oocytes have given inconsistent results. Gangeswaran \& Jones (1997) detected only PKCs $\delta$ and $\lambda$ among nine isozymes using Western blot. Pauken \& Capco (2000) detected PKCs $\alpha, \gamma, \delta, \lambda, \mu$, and $\zeta$ by Western blot and immunocytochemistry, but not PKC $\beta$. While Luria et al. (2000) found that PKCs $\alpha, \beta I$ and $\beta$ II were present by immunocytochemistry, and Downs et al. (2001) found that PKCs $\alpha, \beta \mathrm{I}, \delta$, and $\zeta$, but not $\varepsilon$ were present by Western blot. Luria et al. (2000), Eliyahu \& Shalgi (2002) and Baluch et al. (2004) have supported some of the results with PKC activator/inhibitor studies. In preimplantation embryos, Pauken \& Capco (2000) detected PKCs $\alpha$, $\gamma, \delta, \lambda$, and $\zeta$ but not isoform $\beta$ by Western blot and immunocytochemistry, but Eckert et al. (2004) detected PKCs $\beta \mathrm{I}$ and $\beta \mathrm{II}$ in freshly isolated inner cell masses of mouse blastocysts. Clearly neither Western blot nor immunocytochemistry has provided consistent results with PKC $\beta$.

In this study, we used immunocytochemistry to examine the expression of 10 members of the PKC family $(\alpha, \beta \mathrm{I}, \beta \mathrm{II}$, $\gamma, \delta, \varepsilon, \eta, \theta, \zeta, \iota / \lambda$ ) between the two-cell and blastocyst stages of mouse development. We chose to use immunocytochemistry because it is very sensitive and provides the ability to localize individual PKC isozymes within cells. We included antibodies from two commercial sources that have been widely used in immunocytochemical detection of PKCs, and support the immunocytochemistry data with results from treatments with specific PKC activators. This study differs from previous ones in that we quantified the fluorescence resulting from binding of the antibody to each PKC isozyme. This was done in order to estimate concentrations of each isozyme in various subcellular compartments at various stages of cleavage. This is significant since it has been suggested that small changes in subcellular distribution can lead to functional changes in PKC action. It is difficult to obtain the numbers of preimplantation embryos that would be required for cell fractionation and biochemistry. Quantifying immunofluorescence is one way to circumvent this problem and has been used by others for live cell imaging of PKC translocations (Almholt et al. 1999, Schechtman et al. 2004).

\section{Materials and Methods Embryo collection and treatment}

Mice were maintained and handled in accordance with the guidelines of the Animal Care Committee, University of Guelph, Guelph, Ontario, Canada. Mice (CD1; Charles River, Saint-Constant, QC, Canada) were super-ovulated by intraperitoneal injection of $5 \mathrm{IU}$ pregnant mare's serum gonadotropin followed $46 \mathrm{~h}$ later by $5 \mathrm{IU}$ human chorionic gonadotropin (hCG). Each female mouse was placed with a male and was checked the following morning for the presence of a copulation plug. Embryos (two-cell, fourcell, 8-16-cell, morula, and early blastocyst) were flushed from oviducts or uterine horns with PBS $(8.0 \mathrm{~g} / \mathrm{l} \mathrm{NaCl}$, $0.2 \mathrm{~g} / \mathrm{I} \mathrm{KCl}, 0.15 \mathrm{~g} / \mathrm{Na}_{2} \mathrm{HPO}_{4}$, and $\left.0.2 \mathrm{~g} / \mathrm{KH}_{2} \mathrm{PO}_{4}\right)$ at 45, $52,69,76$, and $93 \mathrm{~h}$ after hCG injection, respectively, as described by Hogan et al. (1994). At these time points, two-cell embryos are in the $\mathrm{G}_{2}$ phase, and four-cell embryos should be in the $\mathrm{G}_{1}$ or $\mathrm{S}$ phase of the cell cycle (Pratt 1987). For most immunofluorescence analysis, the embryos were fixed immediately after harvest and processed as described in the next section.

To study the effects of activating PKC isozymes, two-cell embryos were flushed from oviducts at $45 \mathrm{~h}$ post-hCG with flushing-holding medium (Lawitts \& Biggers 1993), and cultured in $\mathrm{KSOM} / \mathrm{AA}$ medium at $37^{\circ} \mathrm{C}$ under silicone oil in an atmosphere of $5 \% \mathrm{CO}_{2} / 5 \% \mathrm{O}_{2} / 90 \% \mathrm{~N}_{2}$ (Lawitts \& Biggers 1993, Ho et al. 1995) with or without PKC activator. Activation was with $100 \mathrm{nM} 4 \beta$-PMA for $15 \mathrm{~min}$ (LC Laboratories, Woburn, MA, USA) or with $100 \mathrm{nM}$ of the cPKC-activating peptide, pseudo- $\beta$ RACK (where RACK is receptor for activated $C$ kinase) for $60 \mathrm{~min}$ (kindly donated by $\mathrm{D}$ Mochly-Rosen, Department of Molecular Pharmacology, Stanford University School of Medicine, Stanford, CA, USA). The $4 \beta-P M A$ was dissolved in ethanol at $30 \mu \mathrm{M}$ (Watanabe et al. 2002), and used at $100 \mathrm{nM}$ in medium as described for myocytes (Disatnik et al. 1994, Dorn et al. 1999) and similar to what has been used with oocytes (80, 100, and 160 nM; Gallicano et al. 1995, 1997, Raz et al. 1998, Luria et al. 2000). Control embryos were cultured in medium with $0.33 \%$ ethanol. We did not include inactive analogues of $4 \beta-P M A$ because others have shown that the analogues have non-specific activities (for example, see Doerner et al. 1990, Watanabe et al. 2002). The peptide activator pseudo- $\beta$ RACK is cross-linked to a dimer of Antennapedia carrier peptide (CRQIKIWFQNRRMKWKK). This conjugate has been used extensively by MochlyRosen's group, and shown to enter cells and affect PKC distribution and cell function without compromising cell viability (Dorn et al. 1999). This group has also shown 
that pseudo- $\beta$ RACK does not affect distribution of other PKC isoforms at concentrations between $100 \mathrm{nM}$ and $1 \mu \mathrm{M}$, and that scrambled peptide and peptides derived from other parts of the PKC molecule do not affect distribution of the PKC. Negative-control embryos were cultured in medium containing $100 \mathrm{nM}$ carrier-carrier dimer (also kindly donated by D Mochly-Rosen). After culture in treatment or control media, the embryos were immediately fixed and processed for immunocytochemistry.

\section{Immunocytochemistry}

Monoclonal antibodies against seven isozymes of PKC $(\alpha$, $\gamma, \delta, \varepsilon, \theta, \iota$, and $\lambda$ ) and RACK1 were purchased from Transduction Laboratories (Lexington, KY, USA). Polyclonal antibodies raised against specific peptides of nine isozymes of PKC $(\alpha, \beta I, \beta I I, \gamma, \delta, \varepsilon, \zeta, \eta$, and $\theta)$ were purchased from Research \& Diagnostics Antibodies (Berkeley, CA, USA). These antibodies have been previously characterized and used in a number of studies on PKC in embryonic or adult cells (Disatnik et al. 1994, Johnson et al. 1996, Csukai et al. 1997, Miyamae et al. 1998, Dorn et al. 1999, Pauken \& Capco 2000). Embryos were fixed in $2 \%$ paraformaldehyde in PBS for $30 \mathrm{~min}$, and then permeabilized in $0.5 \%$ Triton- $X$ 100 in PBS for $10 \mathrm{~min}$. They were washed three times (20 min each) with $5 \mathrm{mM}$ glycine in PBS, treated with $1 \%$ Tween-20 (10 min), and equilibrated in intracellular buffer (ICB; $100 \mathrm{mM} \mathrm{KCl}, 5 \mathrm{mM} \mathrm{MgCl} 2,3 \mathrm{mM}$ EGTA, 1\% BSA, and $20 \mathrm{mM}$ Hepes, $\mathrm{pH}$ 6.8) for $5 \mathrm{~min}$, as described by Pauken \& Capco $(1999,2000)$. Groups of five embryos were transferred into $50 \mu \mathrm{l}$ drops of ICB containing $10 \%$ serum matching the secondary antibody, $0.1 \%$ Tween-20, and antibody against the PKC isozyme (at a final concentration of $10 \mu \mathrm{g} / \mathrm{ml}$ for monoclonal antibodies and a final dilution of 1:100 for polyclonal antibodies), and incubated overnight at $4{ }^{\circ} \mathrm{C}$. Embryos were washed four times $(30 \mathrm{~min}$ each) with ICB and transferred into $50 \mu$ l drops of diluted secondary antibody at $20 \mu \mathrm{g} / \mathrm{ml}$ for $2 \mathrm{~h}$ at room temperature in the dark. Fluorescein-conjugated, affinity-purified $\mathrm{F}\left(\mathrm{ab}^{\prime}\right)_{2}$ fragment of sheep anti-mouse IgG (Boehringer Mannheim, Mannheim, Germany) was used to detect the monoclonal antibodies, and affinity-purified $F\left(a b^{\prime}\right)_{2}$ fragment of goat anti-rabbit IgG labeled with Rhodamine RedX (Jackson ImmunoResearch Laboratories, West Grove, PA, USA) was used to detect the polyclonal antibodies. The embryos were washed four times $(30 \mathrm{~min}$ each at room temperature in the dark) with ICB and then mounted on $0.1 \%$ poly-lysine coated slides using Vectashield containing 4',6-diamidino-2-phenylindole (DAPI; Vector Laboratories, Burlingame, CA, USA). Negative controls for immunocytochemistry were embryos exposed to medium rather than primary antibody. For each isozyme at each stage, there were at least nine embryos analyzed from three independent experiments.

Imaging was performed using a Bio-Rad MRC 600 confocal laser-scanning microscope attached to an Optiphot-II Nikon fluorescence microscope (with a $60 \times, 1.4$ numerical aperture plan-apochromat oil-immersion objective). Excitation was with 488 and $568 \mathrm{~nm}$ wavelengths from a krypton-argon laser.

\section{Quantification of fluorescence intensity}

We used the same confocal microscope settings for images from all embryos regardless of antibody, and for all trials. The settings were based on the fluorescence intensity of embryos immunostained for PKC $\beta \mathrm{II}$, because this antibody gave us the strongest signal (see Fig. 2C, below). The settings were selected to ensure that the PKC $\beta$ II images were always less than 256 on the gray scale in the highest part of the linear range.

A minimum of three embryos were imaged in three trials on separate days. For each blastomere of each embryo up to the blastocyst stage, an image (optical slice) was selected from the stack that bisected the nucleus and included apical and basal membranes. In our experience, this mid-blastomere slice provides the best single representation of blastomere asymmetry, since the polarized distribution of components in blastomeres is radially disposed. At the blastocyst stage, 10 cells were randomly chosen from the trophectoderm or inner cell mass. The images were converted to TIFF files using Bio-Rad's Confocal Assistant software (version 4.02), and the fluorescence analyzed using Scion Image (Scion Corporation, Frederick, MD, USA). For quantification of fluorescence within the nucleus and cytoplasm, the whole area for nucleus and cytoplasm was selected manually. The cytoplasm was further subdivided by selecting 10 sub-regions (four pixels each) that were immediately sub-adjacent to plasma membrane that was not in contact with another cell (apical cytoplasm), immediately sub-adjacent to plasma membrane that was in contact with another blastomere (basal cytoplasm), or that was midway between these two areas and the nucleus (central cytoplasm).

The mean fluorescence intensity for each subcellular area of each blastomere was calculated by dividing the sum of all gray values in the sub-regions by the total number of pixels enclosed. The background gray value in each image (a region outside of the embryo) was subtracted from the mean fluorescence intensity. Analysis of variance did not show a significant difference between the three trials, and thus we were able to treat the readings from each subcellular area of each blastomere at a given time point as a single population. The error bars in the graphs are the standard deviations of these readings, and represent the variations among blastomeres, embryos, and trials.

Difference in fluorescence intensity between the nucleus and cytoplasm was analyzed using a Student's t-test $(P<0.05)$, and is indicated in Figs $2-5$ (see below) by an asterisk. Differences in fluorescence intensity among the apical, central, and basal regions of the cytoplasm were compared using ANOVA $(P<0.05)$, and the statistically different groups were identified by Tukey's test 
$(P<0.05)$. Statistical difference is indicated by lower-case letters on Figs 2 and 5.

\section{Results}

\section{Specificity of PKC antibodies}

To ascertain that the expression pattern and intracellular location of PKC isozymes are correctly identified, we applied the following measures. First, we compared expression of PKC isozymes using monoclonal and polyclonal antibodies from two sources. Figure 1A shows the staining of both an isozyme-specific monoclonal antibody and polyclonal antiserum from two manufacturers for PKCs $\gamma, \delta, \varepsilon$, and $\theta$. In each case the monoclonal antibodies and polyclonal antisera were raised against two distinct regions of the PKC isozyme, and both antibodies produced the same distribution patterns, although intensity of staining was usually less with the monoclonal antibodies (Fig. 1A). Hence, all further experiments used polyclonal antisera for PKCs $\alpha, \beta \mathrm{I}, \beta \mathrm{II}, \gamma, \delta, \varepsilon, \eta, \theta$, and $\zeta$, and monoclonal antibodies for PKCs $\iota$ and $\lambda$, and RACK1. The monoclonal antibodies that recognize mouse PKCs ı and $\lambda$ cross-react, and the proteins are 99\% homologous (Transduction Laboratories). They are thought to be equivalent genes of human ( $\mathbf{c}$ ) and mouse ( $\lambda$; Kazanietz 2000), so it was reassuring that they displayed almost identical patterns of binding on mouse embryos (see Fig. 5 below). Secondly, the evidence that the antisera against PKCs $\beta \mathrm{I}$ and $\beta$ II detected these PKCs is that $4 \beta$-PMA (a general activator of CPKCs and nPKCs) and pseudo- $\beta$ RACK (a specific peptide activator of cPKCs) affected expression of the molecules detected by these antisera at the two-cell stage. The changes were isozyme-specific, and the same with both types of activation (Fig. 1B); the distributions of
PKCs $\beta I, \beta I I$, and $\gamma$ changed, but PKC $\alpha$ staining remained more concentrated in nuclei, although the nuclear/cytoplasmic ratio decreased. The peptide pseudo$\beta$ RACK was designed using PKC $\beta$ sequence, but from the constant $(\mathrm{C} 2)$ region shared by all cPKCs. Thirdly, whereas all isozymes were detected during preimplantation development, not all isozymes were expressed at every stage. There were negative embryos for some isoforms with each of the two secondary antibodies, one that recognized the polyclonal antisera, and one that recognized the monoclonal antibodies. The stages that were negative for PKCs $\alpha$ and $\gamma$ (Figs 2A and 3A) were stained with the polyclonal secondary, and the stages that were negative for PKCs ı and $\lambda$ and RACK1 (see Fig. 5 below) were stained with the monoclonal secondary. Finally, fluorescence intensity was above that of negative control embryos (no primary antibody) that were part of each trial.

\section{Intracellular distribution of PKC isozymes}

\section{Summary}

The intracellular location of each isozyme was distinctive

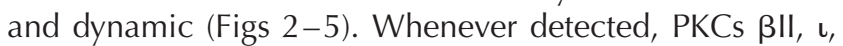
and $\lambda$ and RACK 1 were more concentrated in the cytoplasm than in the nucleus (Figs 2 and 5). The opposite was true of PKC $\eta$; its nuclear concentration was consistently higher than the cytoplasmic concentration except at the late two-cell stage (Fig. 4). For the other PKCs, there were changes in the nuclear/cytoplasmic distribution between stages of preimplantation development. It is interesting that in early four-cell embryos there were more PKCs localized to the nuclei than at any other stage; the concentrations of seven out of 10 isozymes were higher in nuclei than in the cytoplasm.
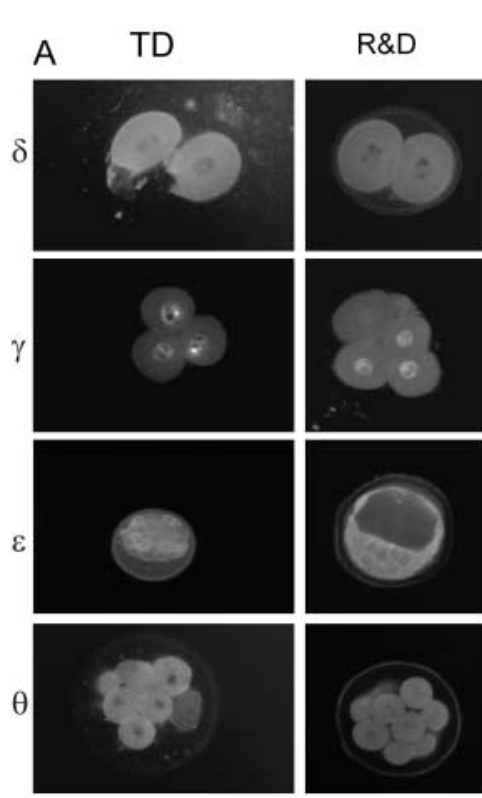

\section{$R \& D$}
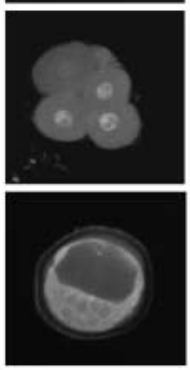

$\alpha$

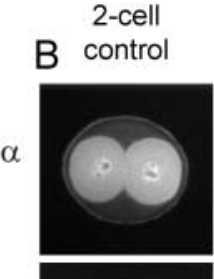

$\beta I$
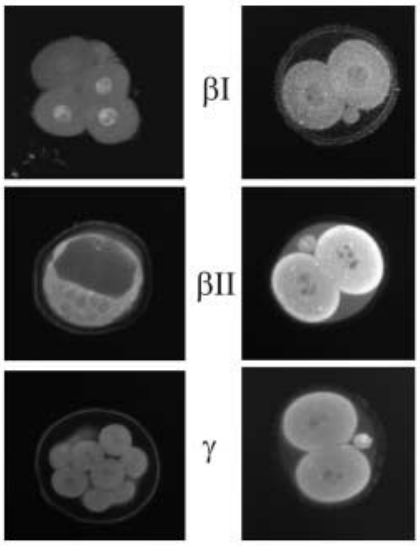

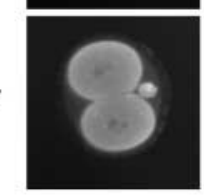

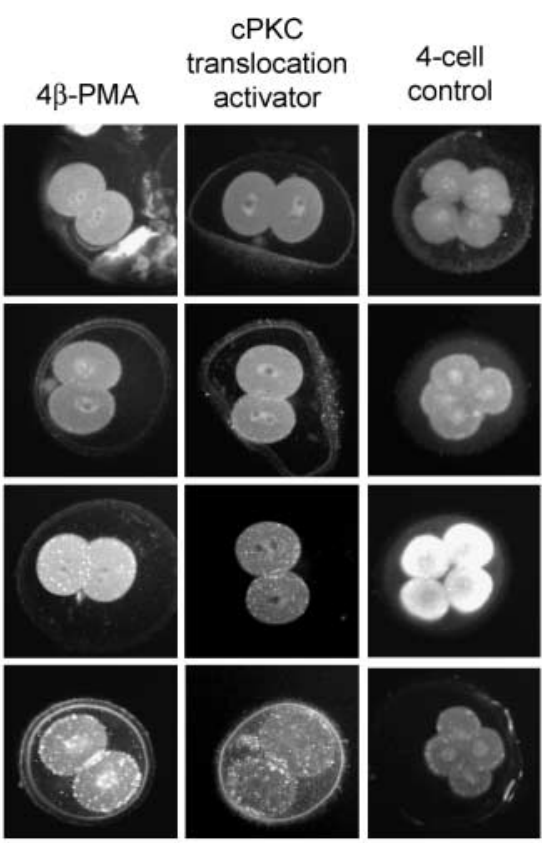

Figure 1 Analysis of antibody specificity. (A) Representative confocal images of two-cell (for PKC $\delta)$, four-cell (for PKC $\gamma$ ), blastocyst (for PKC $\varepsilon$ ), and eight-cell (for PKC $\theta$ ) mouse embryos which were immunostained with antibodies from two different sources. TD, monoclonal antibody, Transduction Laboratories; R\&D, polyclonal antiserum, Research \& Diagnostics Antibodies. (B) Treatment of two-cell embryos with two different activators of CPKC: $15 \mathrm{~min}$ in $100 \mathrm{nM} 4 \beta$-PMA or $60 \mathrm{~min}$ in $100 \mathrm{nM}$ pseudo- $\beta$ RACK. Embryos subsequently were immunostained for each of the CPKC isozymes and examined with a confocal microscope. 

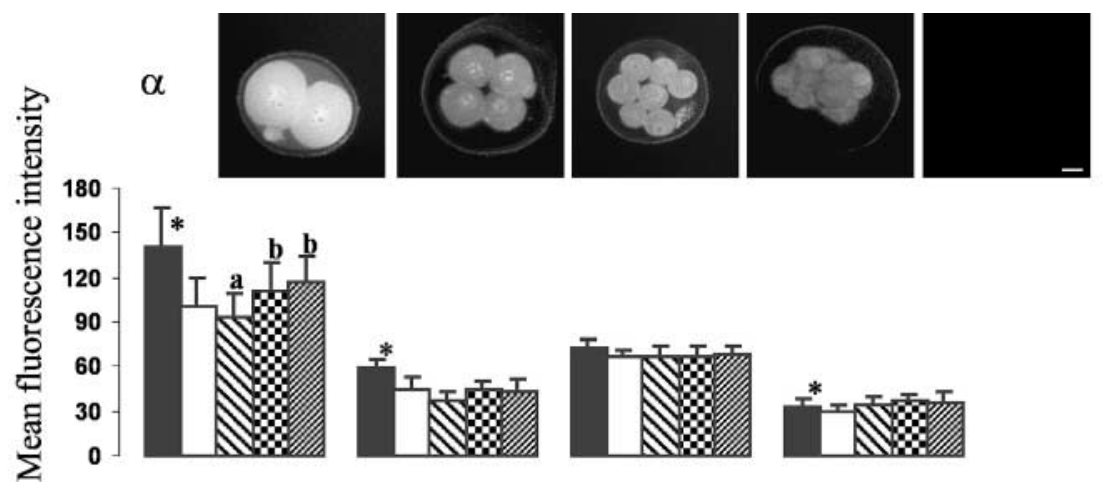

2-cell

4-cell

8- to 16-cell

Morula

Blastocyst
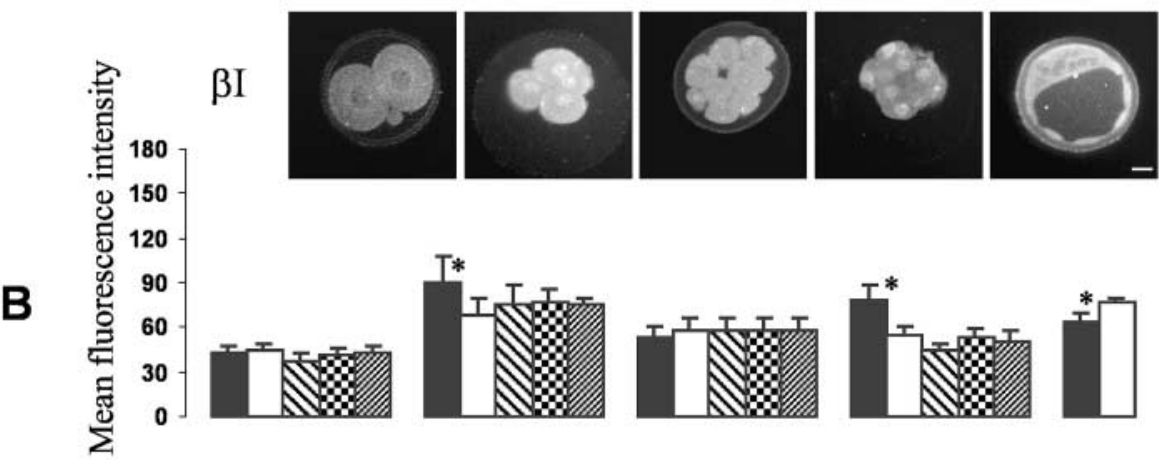

2-cell

4-cell

8- to 16-cell

Morula

Blastocyst
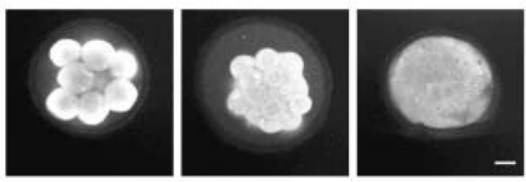

C
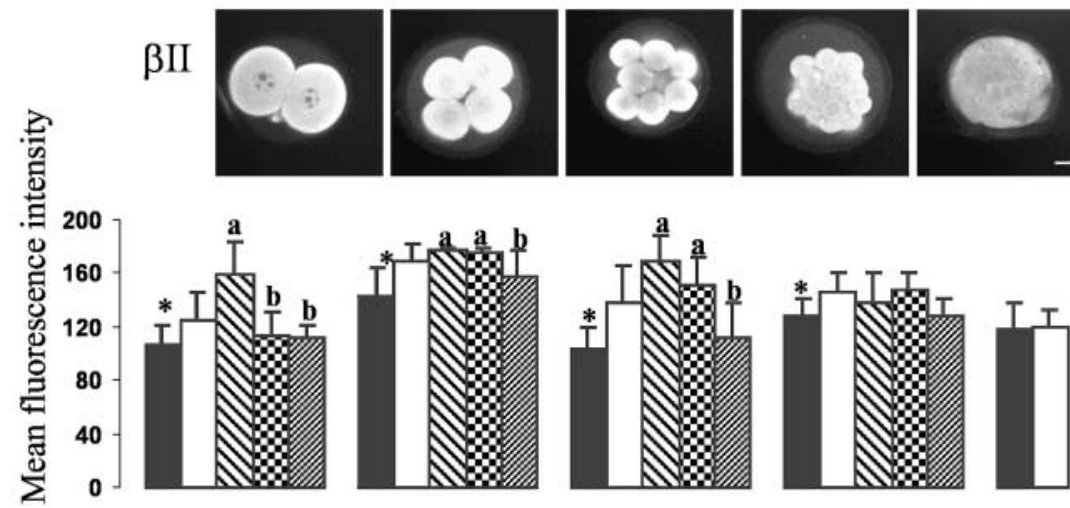

\section{2-cell}

4-cell
Morula \& Central

\section{Blastocyst 践 Basal}

Figure 2 Subcellular localization of PKCs $\alpha, \beta I$, and $\beta I I$ in preimplantation mouse embryos.

A representative confocal image for each preimplantation stage is shown above the histogram.

Mean fluorescence intensity (average gray value of pixels enclosed minus background gray value) was calculated for the nucleus or whole of cytoplasm, and apical, central, and basal cytoplasmic regions of all blastomeres in the embryos of a given stage over three trials. Each bar of the histogram represents the mean fluorescence intensity of all blastomeres in that group, except for blastocysts where 10 blastomeres were selected. Error bars show S.D. values. Significant differences in mean fluorescence intensity between cytoplasmic and nuclear regions are shown by $*, P<0.05$. The letters $a$ and $b$ represent the significant differences among apical, central, and basal regions of the cytoplasm (analyzed by ANOVA and Tukey's test; $P<0.05)$. Two bars with the same letter are statistically similar, and any given bar with unique letter is significantly different from the others. Scale bars, $20 \mu \mathrm{m}$. Note that the optical slice chosen to represent the whole embryo does not bisect all blastomeres in the mid-plane used for analysis. Therefore the image suggests more interblastomeric heterogeneity than exists.

\section{Cytoplasmic versus nuclear distributions}

At the two-cell stage $\left(45 \mathrm{~h}\right.$ post-hCG, $\left.\mathrm{G}_{2}\right)$, PKCs $\beta \mathrm{l}, \delta, \varepsilon$, $\eta, \theta$, and $\zeta$ were distributed equally between the cytoplasmic and nuclear compartments (Figs 2-4). Only PKC $\alpha$ was more concentrated in the nucleus $(P<0.05)$, whereas PKCs $\beta I l, \gamma, \iota$, and $\lambda$ were more concentrated in the cytoplasm $(P<0.05)$.

At the four-cell stage ( $52 \mathrm{~h}$ post-hCG, $\mathrm{G}_{1} / \mathrm{S}$ ), the distributions of PKCs $\alpha, \beta \mathrm{I}, \gamma, \delta, \varepsilon, \eta$, and $\theta$ changed, with six out of seven (all but PKC $\alpha$ ) becoming more concentrated in nuclei $(P<0.05)$. PKC $\alpha$ became equally distributed after being more concentrated in two-cell nuclei. PKC $\iota$ was below the detection limits of the assay.

At the eight-cell stage $(69 \mathrm{~h}$ post-hCG), three out of six PKC isozymes with high nuclear concentrations at the four-cell stage became equally distributed between the cytoplasm and nucleus $(\beta I, \delta$, and $\theta$ ) or became more concentrated in the cytoplasm $(\varepsilon ; P<0.05)$. Only PKCs $\gamma$ and $\eta$ retained higher nuclear fluorescence intensity at this stage $(P<0.05)$. The concentration of PKC $\zeta$ became higher in the cytoplasm from the equal distribution of the four-cell stage $(P<0.05)$. 

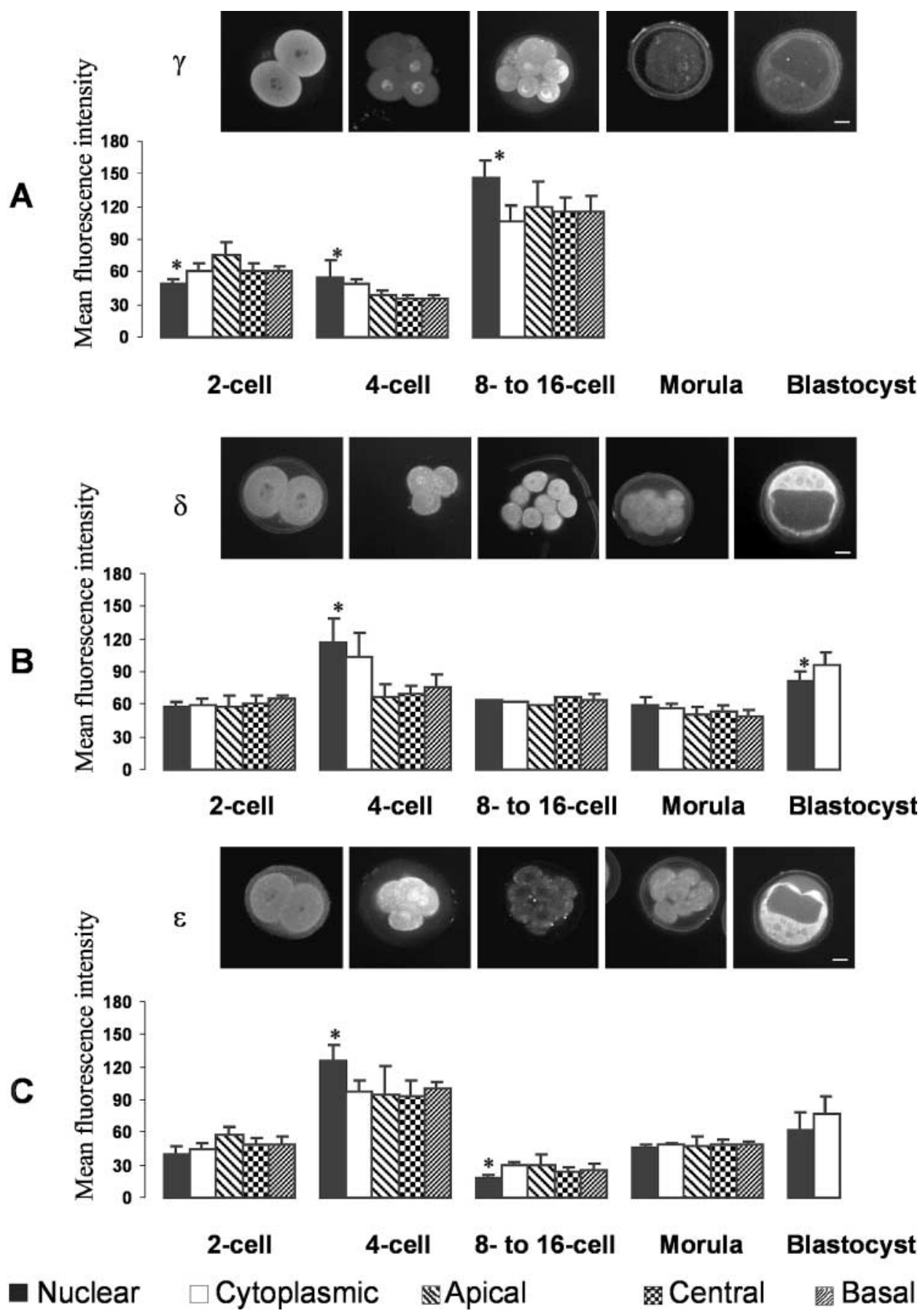

Figure 3 Subcellular localization of PKCs $\gamma, \delta$, and $\varepsilon$ in preimplantation mouse embryos. All details are as for Fig. 2.

At the morula stage ( $76 \mathrm{~h}$ post-hCG), the concentrations of PKC $\alpha, \beta I$, and $\zeta$ once again increased in nuclei $(P<0.05)$, whereas PKCs $\delta$ and $\varepsilon$ became evenly distributed between the nucleus and cytoplasm. Immunostaining for PKCs $\gamma, \mathbf{\iota}$, and $\lambda$ and RACK1 decreased to negative-control levels.

Of the eight PKC isozymes detectable at the blastocyst stage (93 $\mathrm{h}$ post-hCG), PKC $\eta$ was the only isozyme that was more concentrated in the nucleus $(P<0.05)$.

\section{Cytoplasmic distributions}

In the first photomicrographs, there seemed to be uneven distribution within the cytoplasm of some isozymes. Therefore, we separately measured fluorescence in the apical, basal, and central regions of the cytoplasm. At the two-cell stage, PKCs $\beta \mathrm{Il}, \theta, \mathrm{l}$, and $\lambda$ were localized preferentially to the apical cytoplasm $(P<0.05$; Figs 2,4 , and $5)$, and at the four-cell stage RACK1 was localized to the basal cytoplasm ( $P<0.05$; Fig. 5$)$. 


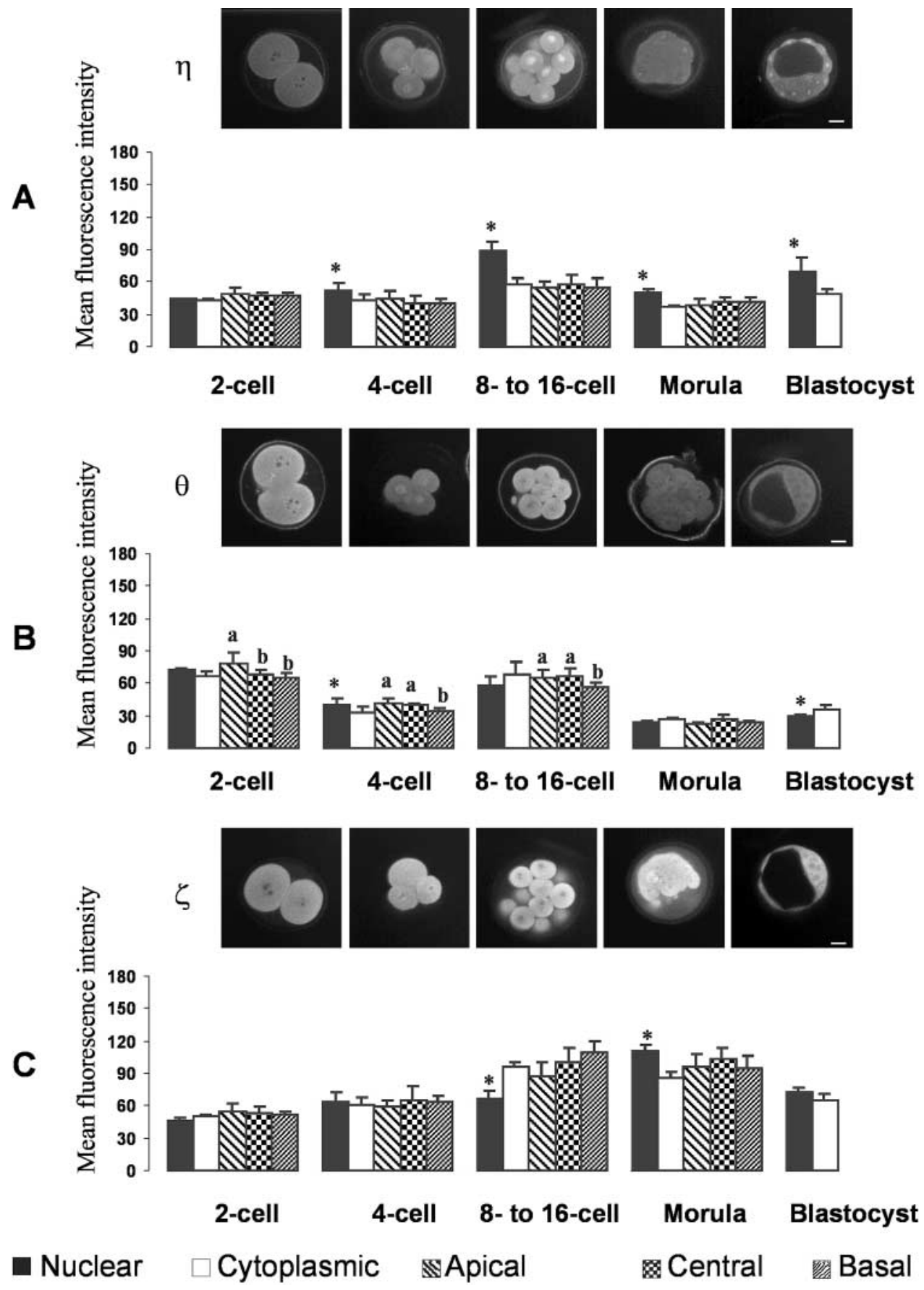

Figure 4 Subcellular localization of PKCs $\eta, \theta$, and $\zeta$ in preimplantation mouse embryos. All details are as for Fig. 2.

\section{Discussion}

\section{Subcellular localization of PKC isozymes}

In this study, we have quantified the relative subcellular concentrations of 10 PKC isozymes and the anchoring protein RACK1 during mouse preimplantation development. To do this we measured the mean fluorescence intensity from subcellular regions (nucleus, cytoplasm, apical cytoplasm, central cytoplasm, and basal cytoplasm) of all blastomeres of embryos immunostained for a PKC

isozyme up to the blastocyst stage. Since the fluorescence intensity of the embryo depends on the quantity of primary antibody-secondary antibody associations, it is an indicator of the amount of each isozyme. Because the number of antibody-binding sites and affinities are uncertain, the assay does not measure the absolute amount of isozyme, or allow quantitative comparison between isozymes. Therefore, the assay is semi-quantitative. However, by maintaining antibody reaction conditions, by using the same confocal microscope settings, and by averaging three independent trials, the assay does produce 


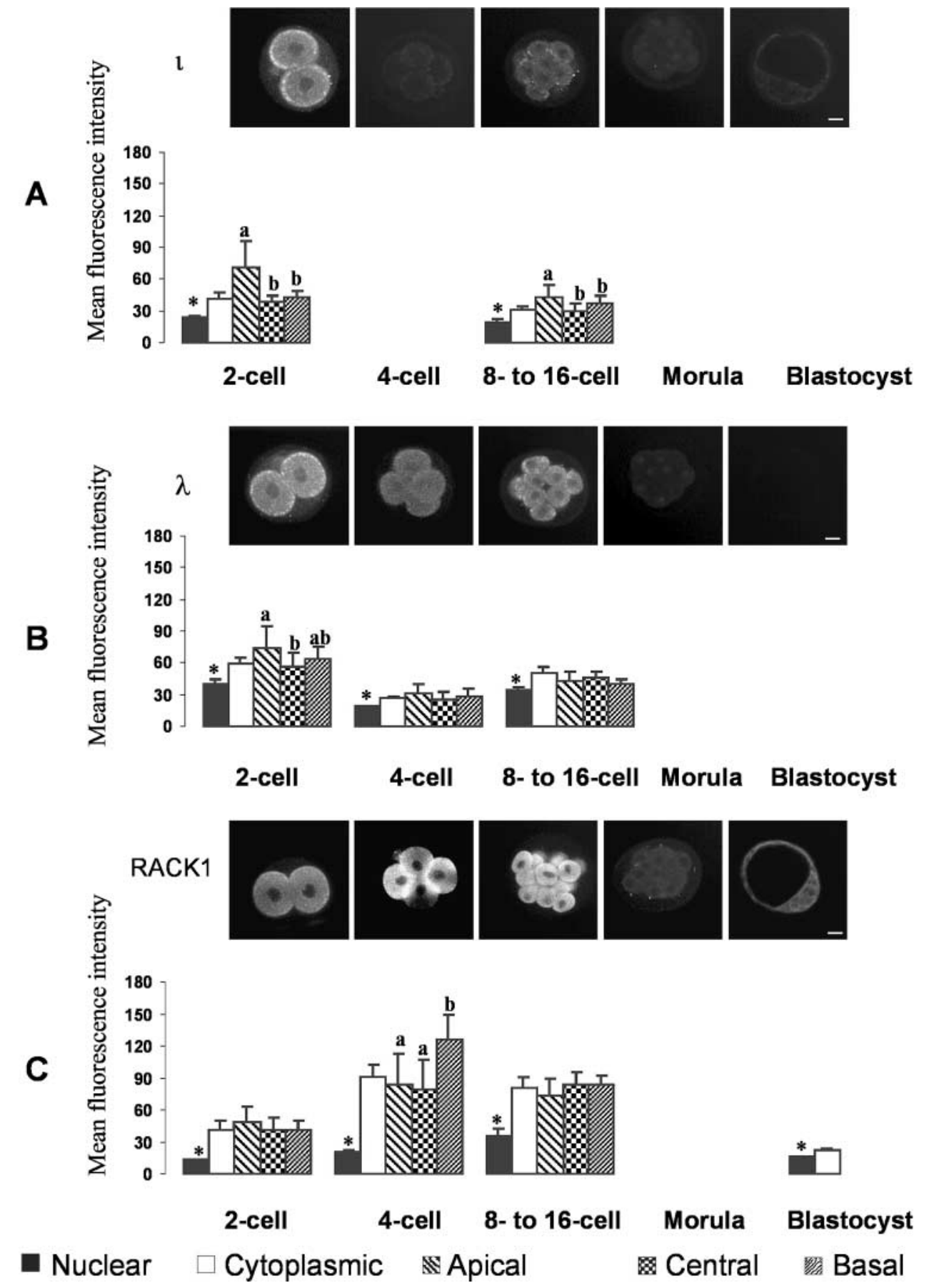

Figure 5 Subcellular localization of PKCs $\iota$ and $\lambda$, and the anchoring protein RACK1 in preimplantation mouse embryos. All details are as for Fig. 2. information on relative concentrations (fluorescence intensity) of a single isozyme between subcellular compartments and between stages. In the accompanying study (Dehghani et al. 2005), the ratio of nuclear to cytoplasmic fluorescence is calculated as a way to accommodate intertrial variation in staining intensity. This calculation was not performed in this study because various parts of the cytoplasm as well as the whole of the cytoplasm are examined. Also, fluxes in concentration between stages are indicated by the data in this form that would not be seen with ratios. On the other hand, variability in staining between trials may have reduced sensitivity of the analysis. Finally, the zona pellucida was not removed prior to immunostaining, following the protocol of Pauken \& Capco (1999). This was to fix embryos as soon as possible after recovery. Trapping of antibody in the zona pellucida could have caused the absence of staining of blastocysts with some of the antibodies. However, it seemed that the amount of antibody trapped varied more with trial than stage or antibody.

In most studies with adult cell types, PKC in different subcellular fractions has been detected by Western blots 
using $200 \mu \mathrm{g}-1 \mathrm{mg}$ protein, depending on isozyme abundance. Similar studies with preimplantation embryos certainly would be hampered by lack of material. A mouse oocyte has approximately $23 \mathrm{ng}$ total protein (Hogan et al. 1994). However, live-cell imaging of translocation in individual cells, imaging for co-localization of intracellular signaling molecules, and photobleaching studies have quantified relative fluorescence intensity (Almholt et al. 1999, Ron et al. 1999, Echevarria et al. 2003, Schechtman et al. 2004). Thus whereas quantifying fluorescence intensity is not novel, it has not been used to localize signaling molecules in preimplantation mammalian embryos in quite this manner. The success of the approach is seen in the fact that differences were detected between the nucleus and cytoplasm and different areas of the cytoplasm. Thus, this approach should be effective for studying intracellular distribution and associations of molecules in preimplantation embryos where starting material is too limited for cell fractionation.

There are differences between this study and that of Pauken \& Capco (2000) especially in the subcellular distribution of PKCs $\alpha, \gamma$, and $\zeta$. More recently, Quan et al. (2003) and Baluch et al. (2004) have shown PKC $\alpha$ distribution similar to ours. However, discrepancies in distribution will likely remain since distribution of PKC is dynamic, and precisely when and how embryos are collected could affect results. In this study, we controlled timing of gonadotrophin administration and embryo collection as much as possible. The major difference between this study and that of Pauken \& Capco (2000) is the presence of PKCs $\beta \mathrm{I}$ and $\beta \mathrm{II}$. Pauken \& Capco found no PKC $\beta$ in preimplantation mouse embryos. However, Eckert et al. (2004) detected both PKCs $\beta I$ and $\beta I$ in freshly isolated mouse inner cell masses. The expression of the PKC $\beta$ isoforms in mouse oocytes has been similarly controversial using both Western blots and immunofluorescence (Gangeswaran \& Jones 1997, Luria et al. 2000, Pauken \& Capco 2000, Downs et al. 2001). Because of this, we decided to use activation as a means to verify antibody specificity. The fact that both general and specific peptide activators of the CPKC caused translocation of the molecules recognized by our antibodies against PKCs $\beta I$ and $\beta$ II suggests that what is recognized are PKC $\beta$, or at least PKC $\beta$-like, molecules.

Localization of PKC isozymes to subcellular compartments can be mediated by binding to isozyme-specific anchoring proteins or through the cytoskeleton (MochlyRosen \& Gordon 1998, Jaken \& Parker 2000, Newton 2001, Schechtman \& Mochly-Rosen 2001). Known anchoring proteins include substrates that interact with $\mathrm{C}$ kinases (STICKs) and isozyme-specific RACKs. Most known STICKs are located at interfaces between membranes and cytoskeletal structures, and phosphorylation by PKC modifies their function. They may or may not be multi-enzyme scaffold proteins. An example of the latter is AKAP 79, which binds to PKCs $\alpha$ and $\beta$ II (Klauck et al. 1996), as well as at least two other signal transducers, protein kinase $\mathrm{A}$ and calcineurin $\left(\mathrm{a} \mathrm{Ca}^{2+} /\right.$ calmodulindependent phosphatase). RACK1 is a non-substrate receptor for PKC $\beta I I$, although it also binds other PKC isoforms and other molecules (Jaken \& Parker 2000, Rigas et al. 2003). Since RACK1 is involved in the translocation and association of PKC $\beta$ II with a normal substrate in cardiac myocytes (Ron \& Mochly-Rosen 1995, Csukai et al. 1997), it is interesting that RACK1 and PKC $\beta$ II distributions differ in preimplantation embryos. In particular, RACK 1 is concentrated in the basal region of cytoplasm in four-cell stage embryos, whereas PKC $\beta$ II is concentrated in the apical cytoplasm. Other RACKs, STICKs, or a receptor for inactivated C kinase (RICK) may govern PKC $\beta$ II localization at this stage. Further studies to find molecular partners of PKC isozymes are needed to elucidate their localization and function.

Although translocation of PKC is associated with activation in other cell types (Csukai \& Mochly-Rosen 1999, Teruel \& Meyer 2000), it must be noted that the state of activation of each isozyme during preimplantation development still needs to be determined. Also, there are several sources of change in the relative concentration of an isozyme observed in this study. First, there could be translocation of existing molecules between the cytoplasm and nucleus or of newly synthesized protein from the cytoplasm into the nucleus. Second, new synthesis of an isozyme without translocation would increase the relative cytoplasmic concentration. Or thirdly there could be differential degradation of an isozyme among subcellular compartments, which would decrease the relative concentration in that compartment. Further studies with individual isozymes to separate these possibilities are in order.

\section{Functional implications of subcellular localization of PKC isozymes}

This study defines the intracellular distribution of each PKC isozyme at specific times during cleavage, because it is subcellular location of PKC isozymes that correlates with different functions in a cell (Newton 2001). In adult cells, the PKC isozymes have a large and varied number of regulatory roles. Regulation of nuclear architecture (Hocevar et al. 1993, Maraldi et al. 1999), cell cycle (Livneh \& Fishman 1997), and cellular polarization (Plant et al. 2003) are just a few examples. The PKC isozymes translocate to different subcellular areas during preimplantation mouse development, and likely are involved in multiple steps in preimplantation development. We found that nuclear localization of PKC $\alpha$ (early two- and four-cell nuclei) overlaps with that of PKC $\gamma$ (four- and eight-cell nuclei), whereas PKCs $\delta$ and $\varepsilon$ are more concentrated in nuclei only at the early four-cell stage (Figs 2 and 3). Furthermore, we found that PKC $\eta$ localizes to the nuclei of eight-cell- to blastocyst-stage embryos (Fig. 4). Nuclear localization may indicate involvement in regulation of transcription. Hamatani et al. (2004) have shown increases in the number of genes transcribed at each stage of mouse preimplantation development. There is also 
evidence for chromatin remodeling in early mouse embryos (Thompson et al. 1998, Schultz et al. 1999). Recently, Santos et al. (2003) and Sarmento et al. (2004) have described constant modulation of histones during this period. It is very likely that some of the PKCs are involved in changing the relative lengths of the cell-cycle components during early cleavage (Pratt 1987, Livneh \& Fishman 1997).

In conclusion, this study suggests fertile areas for further research. Activation state, effects of specific inhibitors and activators, co-localization with potential substrates and regulators, and temporal and spatial correlation of the isozymes with specific processes of mouse preimplantation embryogenesis are studies that can be undertaken in the future using this semi-quantitative approach. In the accompanying paper (Dehghani et al. 2005), we study the relationship between translocation of PKCs $\delta$ and $\varepsilon$ into four-cell nuclei and transcription and nuclear morphology.

\section{Acknowledgements}

We thank Dr Mochly-Rosen for providing the isozymespecific translocation activator of CPKC. This work was supported by a NSERC Canada grant to $\mathrm{A} \mathrm{C} \mathrm{H}$, and $\mathrm{H}$ D was supported by a scholarship from MCHE Iran. The authors declare that there is no conflict of interest that would prejudice the impartiality of this scientific work.

\section{References}

Almholt K, Arkhammar PO, Thastrup O \& Tullin S 1999 Simultaneous visualization of the translocation of protein kinase Calpha-green fluorescent protein hybrids and intracellular calcium concentrations. Biochemical Journal 337 211-218.

Baluch DP, Koeneman BA, Hatch KR, McGaughey RW \& Capco DG 2004 PKC isotypes in post-activated and fertilized mouse eggs: association with the meiotic spindle. Developmental Biology 274 45-55.

Csukai M \& Mochly-Rosen D 1999 Pharmacologic modulation of protein kinase C isozymes: the role of RACKs and subcellular localisation. Pharmacological Research 39 253-259.

Csukai M, Chen CH, De Matteis MA \& Mochly-Rosen D 1997 The coatomer protein beta'-COP, a selective binding protein (RACK) for protein kinase Cepsilon. Journal of Biological Chemistry 272 29200-29206.

Dehghani H, Reith C \& Hahnel AC 2005 Subcellular localization of protein kinase $C \delta$ and $\varepsilon$ affects transcriptional and post-transcriptional processes in four-cell mouse embryos. Reproduction 130 453-465.

Disatnik MH, Buraggi G \& Mochly-Rosen D 1994 Localization of protein kinase $\mathrm{C}$ isozymes in cardiac myocytes. Experimental Cell Research $210287-297$.

Doerner D, Abdel-Latif M, Rogers TB \& Alger BE 1990 Protein kinase C-dependent and independent effects of phorbol esters on hippocampal calcium channel current. Journal of Neuroscience $\mathbf{1 0}$ 1699-1706.

Dorn GW 2nd, Souroujon MC, Liron T, Chen CH, Gray MO, Zhou HZ, Csukai M, Wu G, Lorenz JN \& Mochly-Rosen D 1999 Sustained in vivo cardiac protection by a rationally designed peptide that causes epsilon protein kinase C translocation. PNAS 96 12798-12803.
Downs SM, Cottom J \& Hunzicker-Dunn M 2001 Protein kinase C and meiotic regulation in isolated mouse oocytes. Molecular Reproduction and Development 58 101-115.

Echevarria W, Leite MF, Guerra MT, Zipfel WR \& Nathanson MH 2003 Regulation of calcium signals in the nucleus by a nucleoplasmic reticulum. Nature Cell Biology 5 440-446.

Eckert J, McCallum A, Mears A, Rumsby MG, Cameron IT \& Fleming TP 2004 PKC signalling regulates tight junction membrane assembly in the pre-implantation mouse embryo. Reproduction $127653-667$.

Eliyahu E \& Shalgi R 2002 A role for protein kinase C during rat egg activation. Biology of Reproduction 67 189-195.

Fan HY, Tong C, Li MY, Lian L, Chen DY, Schatten H \& Sun QY 2002 Translocation of the classic protein kinase $\mathrm{C}$ isoforms in porcine oocytes: implications of protein kinase $\mathrm{C}$ involvement in the regulation of nuclear activity and cortical granule exocytosis. Experimental Cell Research 277 183-191.

Gallicano GI, McGaughey RW \& Capco DG 1995 Protein kinase M, the cytosolic counterpart of protein kinase $\mathrm{C}$, remodels the internal cytoskeleton of the mammalian egg during activation. Developmental Biology $167482-501$.

Gallicano GI, McGaughey RW \& Capco DG 1997 Activation of protein kinase $\mathrm{C}$ after fertilization is required for remodeling the mouse egg into the zygote. Molecular Reproduction and Development 46 587-601.

Gangeswaran R \& Jones KT 1997 Unique protein kinase C profile in mouse oocytes: lack of calcium-dependent conventional isoforms suggested by rtPCR and Western blotting. FEBS Letters $\mathbf{4 1 2}$ 309-312.

Geiges D, Meyer T, Marte B, Vanek M, Weissgerber G, Stabel S et al. 1997 Activation of protein kinase $\mathrm{C}$ subtypes alpha, gamma, delta, epsilon, zeta, and eta by tumor-promoting and nontumor-promoting agents. Biochemical Pharmacology 53 865-875.

Hamatani T, Carter MG, Sharov AA \& Ko MS 2004 Dynamics of global gene expression changes during mouse preimplantation development. Developmental Cell 6 117-131.

Hausser A, Link G, Bamberg L, Burzlaff A, Lutz S, Pfizenmaier K \& Johannes FJ 2002 Structural requirements for localization and activation of protein kinase $\mathrm{C}$ mu (PKC mu) at the Golgi compartment. Journal of Cell Biology 156 65-74.

Ho Y, Wigglesworth K, Eppig JJ \& Schultz RM 1995 Preimplantation development of mouse embryos in KSOM: augmentation by amino acids and analysis of gene expression. Molecular Reproduction and Development 41 232-238.

Hocevar BA, Burns DJ \& Fields AP 1993 Identification of protein kinase C (PKC) phosphorylation sites on human lamin B. Potential role of PKC in nuclear lamina structural dynamics. Journal of Biological Chemistry 268 7545-7552.

Hogan B, Beddington R, Costantini F \& Lacy E 1994 In Manipulating the Mouse Embryo, a Laboratory Manual. New York: Cold Spring Harbor Press.

Jaken S \& Parker PJ 2000 Protein kinase C binding partners. Bioessays 22 245-254.

Johnson JA, Gray MO, Chen CH \& Mochly-Rosen D 1996 A protein kinase $\mathrm{C}$ translocation inhibitor as an isozyme-selective antagonist of cardiac function. Journal of Biological Chemistry 271 $24962-24966$.

Kazanietz MG 2000 Eyes wide shut: protein kinase C isozymes are not the only receptors for the phorbol ester tumor promoters. Molecular Carcinogenesis 28 5-11.

Keranen LM, Dutil EM \& Newton AC 1995 Protein kinase C is regulated in vivo by three functionally distinct phosphorylations. Current Biology 5 1394-1403.

Klauck TM, Faux MC, Labudda K, Langeberg LK, Jaken S \& Scott JD 1996 Coordination of three signaling enzymes by AKAP79, a mammalian scaffold protein. Science 271 1589-1592.

Lawitts JA \& Biggers JD 1993 Culture of preimplantation embryos. Methods in Enzymology 225 153-164. 
Livneh E \& Fishman DD 1997 Linking protein kinase C to cell-cycle control. European Journal of Biochemistry 248 1-9.

Luria A, Tennenbaum T, Sun QY, Rubinstein S \& Breitbart H 2000 Differential localization of conventional protein kinase $C$ isoforms during mouse oocyte development. Biology of Reproduction 62 $1564-1570$

Maraldi NM, Zini N, Santi S \& Manzoli FA 1999 Topology of inositol lipid signal transduction in the nucleus. Journal of Cell Physiology $181203-217$

Miyamae M, Rodriguez MM, Camacho SA, Diamond I, MochlyRosen D \& Figueredo VM 1998 Activation of epsilon protein kinase C correlates with a cardioprotective effect of regular ethanol consumption. PNAS 95 8262-8267.

Mochly-Rosen D \& Gordon AS 1998 Anchoring proteins for protein kinase C: a means for isozyme selectivity. FASEB Journal 12 35-42.

Mochly-Rosen D \& Kauvar LM 2000 Pharmacological regulation of network kinetics by protein kinase C localization. Seminars in Immunology 12 55-61.

Newton AC 2001 Protein kinase C: structural and spatial regulation by phosphorylation, cofactors, and macromolecular interactions. Chemistry Reviews 101 2353-2364.

Ohsugi M \& Yamamura H 1993 Differences in the effects of treatment of uncompacted and compacted mouse embryos with phorbol esters on pre- and postimplantation development. Differentiation 53 173-179.

Ohsugi M, Ohsawa T \& Semba R 1993a Similar responses to pharmacological agents of 1,2-OAG-induced compaction-like adhesion of two-cell mouse embryo to physiological compaction. Journal of Experimental Zoology 265 604-608.

Ohsugi M, Ohsawa T \& Yamamura H $1993 b$ Involvement of protein kinase $\mathrm{C}$ in nuclear migration during compaction and the mechanism of the migration: analyses in two-cell mouse embryos. Developmental Biology 156 146-154.

Pauken CM \& Capco DG 1999 Regulation of cell adhesion during embryonic compaction of mammalian embryos: roles for PKC and beta-catenin. Molecular Reproduction and Development $\mathbf{5 4}$ 135-144.

Pauken CM \& Capco DG 2000 The expression and stage-specific localization of protein kinase $C$ isotypes during mouse preimplantation development. Developmental Biology 223 411-421.

Plant PJ, Fawcett JP, Lin DC, Holdorf AD, Binns K, Kulkarni S \& Pawson T 2003 A polarity complex of mPar-6 and atypical PKC binds, phosphorylates and regulates mammalian Lgl. Nature Cell Biology 5 301-308.

Pratt HPM 1987 Isolation, Culture, and Manipulation of Preimplantation Mouse Embryos. In Mammalian Development: A Practical Approach, pp 13-42. Ed M Monk. Washington DC: IRL Press.

Quan HM, Fan HY, Meng XQ, Huo LJ, Chen DY, Schatten H, Yang PM \& Sun QY 2003 Effects of PKC activation on the meiotic maturation, fertilization and early embryonic development of mouse oocytes. Zygote 11 329-337.

Raz T, Eliyahu E, Yesodi V \& Shalgi R 1998 Profile of protein kinase $\mathrm{C}$ isozymes and their possible role in mammalian egg activation. FEBS Letters 431 415-418.

Rigas AC, Ozanne DM, Neal DE \& Robson CN 2003 The scaffolding protein RACK1 interacts with androgen receptor and promotes cross-talk through a protein kinase C signaling pathway. Journal of Biological Chemistry 278 46087-46093.

Ron D \& Mochly-Rosen D 1995 An autoregulatory region in protein kinase C: the pseudoanchoring site. PNAS 92 492-496.
Ron D, Jiang Z, Yao L, Vagts A, Diamond I \& Gordon A 1999 Coordinated movement of RACK1 with activated betallPKC. Journal of Biological Chemistry 274 27039-27046.

Santos F, Zakhartchenko V, Stojkovic M, Peters A, Jenuwein T, Wolf E, Reik W \& Dean W 2003 Epigenetic marking correlates with developmental potential in cloned bovine preimplantation embryos. Current Biology 13 1116-1121.

Sarmento OF, Digilio LC, Wang Y, Perlin J, Herr JC, Allis CD \& Coonrod SA 2004 Dynamic alterations of specific histone modifications during early murine development. Journal of Cell Science 117 4449-4459.

Schechtman D \& Mochly-Rosen D 2001 Adaptor proteins in protein kinase C-mediated signal transduction. Oncogene $\mathbf{2 0}$ 6339-6347.

Schechtman D, Craske ML, Kheifets V, Meyer T, Schechtman J \& Mochly-Rosen D 2004 A critical intramolecular interaction for protein kinase Cepsilon translocation. Journal of Biological Chemistry $27915831-15840$.

Schultz RM 1993 Regulation of zygotic gene activation in the mouse. Bioessays 15 531-538.

Schultz RM, Davis W Jr, Stein P \& Svoboda P 1999 Reprogramming of gene expression during preimplantation development. Journal of Experimental Zoology 285 276-282.

Stachecki JJ \& Armant DR 1996 Regulation of blastocoele formation by intracellular calcium release is mediated through a phospholipase C-dependent pathway in mice. Biology of Reproduction $\mathbf{5 5}$ $1292-1298$.

Teruel MN \& Meyer T 2000 Translocation and reversible localization of signaling proteins: a dynamic future for signal transduction. Cell $103181-184$.

Thompson EM, Legouy E \& Renard JP 1998 Mouse embryos do not wait for the MBT: chromatin and RNA polymerase remodeling in genome activation at the onset of development. Developments in Genetics 22 31-42.

Viveiros MM, Hirao Y \& Eppig JJ 2001 Evidence that protein kinase C (PKC) participates in the meiosis I to meiosis II transition in mouse oocytes. Developments in Biology 235 330-342.

Viveiros MM, O'Brien M, Wigglesworth K \& Eppig JJ 2003 Characterization of protein kinase C-delta in mouse oocytes throughout meiotic maturation and following egg activation. Biology of Reproduction 69 1494-1499.

Wang S, Gebre-Medhin S, Betsholtz C, Stalberg P, Zhou Y, Larsson C, Weber G, Feinstein R, Oberg K, Gobl A \& Skogseid B 1998 Targeted disruption of the mouse phospholipase $C$ beta3 gene results in early embryonic lethality. FEBS Letters $\mathbf{4 4 1}$ $261-265$.

Watanabe H, Davis JB, Smart D, Jerman JC, Smith GD, Hayes P, Vreins J, Cairns W, Wissenbach U, Prenen J, Flockerzi V, Droogemans G, Benham CD \& Nilus B 2002 Activation of TRPV4 channels (hVRL-2/mTRP12) by phorbol derivatives. Journal of Biological Chemistry 277 13569-13577.

Winkel GK, Ferguson JE, Takeichi M \& Nuccitelli R 1990 Activation of protein kinase $C$ triggers premature compaction in the four-cell stage mouse embryo. Developmental Biology 138 1-15.

Received 15 November 2004

First decision 6 January 2005

Revised manuscript received 22 March 2005

Accepted 21 June 2005 